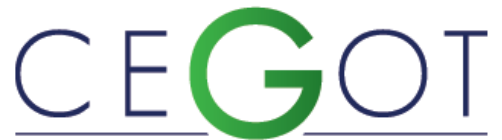

Centro de Estudos de Geografia e Ordenamento do Território
Geografia e Ordenamento do Território, Revista Eletrónica Centro de Estudos de Geografia e Ordenamento do Território http://cegot.org

TONETTO, LEANDRO

UNISINOS - Universidade do Vale do Rio dos Sinos, Design, $P P G$

90470280, Av. Nilo Peçanha, 1640, Porto Alegre/RS, Brasil Itonetto@unisinos.br

TAROUCO, FABRÍCIO

UNISINOS - Universidade do Vale do Rio dos Sinos,

Arquitetura e Urbanismo, PPG

90470280, Porto Alegre/RS, Brasil

ftarouco@unisinos.br

COSTA, FILIPE

UNISINOS - Universidade do Vale do Rio dos Sinos, Design, $P P G$

90470280, Porto Alegre/RS, Brasil

fcampelo@unisinos.br

\title{
Cidades turísticas e a projetação de valor emocional para as pessoas através de ambientes construídos
}

Touristic cities and the design of emotional value to people through built environments

Referência: Tonetto, Leandro; Tarouco, Fabrício; Costa, Filipe (2018). Cidades turísticas e a projetação de valor emocional para as pessoas através de ambientes construídos. Revista de Geografia e Ordenamento do Território (GOT), n. ${ }^{\circ} 13$ (junho). Centro de Estudos de Geografia e Ordenamento do Território, p. 435-458, dx.doi.org/10.17127/got/2018.13.019

\section{RESUMO}

O turismo é um importante elemento para a economia e para a identidade de muitas cidades. O objetivo desta pesquisa foi compreender, a partir das avaliações dos turistas, quais são as experiências emocionais mais comuns vividas em suas cidades favoritas, e quais elementos as evocam. Adotou-se, para tanto, a Teoria dos Appraisals como modelo de investigação. Ela estabelece que as emoções experimentadas derivam da forma como os turistas processam as informações sobre o ambiente. A pesquisa, de base quantitativa, teve uma amostra de 310 pessoas e identificou cinco tipos de experiências emocionais que definem a preferência da pessoa por uma cidade: altruísmo/solidariedade, diversão, alegria, vínculo com o território e quebra de expectativas, sendo que cada uma pode ser incitada a partir de estímulos específicos.

Palavras-chave: Cidades; Turismo; Design Emocional.

\section{ABSTRACT}

Tourism is an important element to many cities' economies and identities. This research was aimed at understanding, through tourist appraisals, which are the most common emotional experiences they encounter in their favourite cities, and which elements that can evoke these experiences. Appraisal Theory was the evaluation model adopted in this research. It indicates that the emotions people experience in a certain place are results of how they evaluate (appraise) information about the environment. The research has a quantitative 
basis, and 310 people took part in the study. Results have shown that there are five types of emotional experiences that shape a person's preference for a city: altruism/solidarity, fun, joy, bond with the territory and expectation disconfirmation. According to these results, each kind of experience can be evoked by specific stimuli.

Keywords: Cities; Tourism; Emotional Design.

\section{Introdução}

Cada vez mais, diversas cidades vêm se esforçando para se posicionarem como importantes destinos turísticos. Para isso, gestores e comunidade projetam experiências, qualificam a paisagem e os atrativos, bem como fortalecem a infraestrutura local, comumente no intuito de receber novos visitantes. É sabido que os motivos que podem despertar o interesse das pessoas são estímulos naturais, como uma orla, por exemplo, ou experiências projetadas, como feiras, exposições e apresentações artísticas. Dessa forma, consolidou-se uma forma de turismo nas cidades focado na experiência dos indivíduos.

Qualificar uma cidade apenas a partir da visão de turistas seria questionável, pois desconsideraria demandas locais daqueles que vivenciam o território no seu quotidiano. No entanto, as experiências positivas vividas pelas pessoas representam um importante elemento para a consolidação de uma cidade que deseja posicionar-se como turística, motivo pelo qual o presente artigo foca nessas vivências em particular.

No caso das cidades, a paisagem urbana e os eventos que nela acontecem podem ser entendidos como motivadores do turismo. Oliveira, Anjos e Leite (2008) afirmam que, em Brasília (Brasil), por exemplo, o potencial atrativo do ambiente urbano é um expoente, já que sua configuração é imprescindível no processo de apropriação da paisagem pelo visitante. Reality tours, nessa direção, também são exemplos de alternativas para o turista, mesmo que as atividades pareçam contemplar apenas seus desejos, sem representar uma real contribuição aos moradores, como no caso das favelas (FREIRE-MEDEIROS, 2007).

O turismo, por um lado, tem o potencial de beneficiar as comunidades locais, por meio da geração de atividades laborais e desenvolvimento econômico, e, por outro, envolve expectativas de satisfação de necessidades psicológicas do visitante, como recompensa por um período de trabalho, busca de status, de autoexpressão e de envolvimento social (SWARBROOKE; HORNER, 2002). Para que atenda a ambas as demandas, é preciso que a cidade disponha de serviços, instalações e atributos atrativos para o turista. 
Sendo assim, o turismo voltado à experiência carrega em si uma importante característica: ele interfere nos aspectos emocionais do visitante. Portanto, uma área que pode ser aliada ao estudo das vivências das pessoas é o design emocional, que vem se dedicando a pensar projetos de produtos, serviços e experiências territoriais com o objetivo de provocar ou evitar dado tipo de reação (DESMET, 2009). Nessa área, comumente são investigados os aspectos tangíveis de uma experiência emocional, como a inspiração, a admiração ou a positividade que podem ser provocadas por um local, a fim de fomentar projetos que possam tomar como base os gatilhos mais comuns dessas vivências.

Uma das abordagens mais amplamente utilizadas na área é a Teoria dos Appraisals (FRIJDA, 1986; LAZARUS, 1991; DESMET, 2002; DEMIR, DESMET E HEKKERT, 2009). A partir dela, compreende-se que a experiência emocional é resultado da forma como a pessoa avalia (appraisal) estímulos ambientais e seus impactos sobre seu bem-estar.

O modelo de investigação de avaliações tem base em sete componentes, que facilitam, por parte dos profissionais, a visualização dos elementos projetuais com foco em uma experiência. Cada uma das sete dimensões referidas pode ser representada por uma questão, conforme é possível observar no Quadro 1.

\begin{tabular}{l|l}
$\begin{array}{c}\text { Componente de } \\
\text { Avaliação }\end{array}$ & \multicolumn{1}{c}{ Conceito e exemplo de questão relacionada } \\
\hline $\begin{array}{l}\text { Consistência do } \\
\text { Motivo }\end{array}$ & $\begin{array}{l}\text { Avalia em que medida a motivação da visita a uma cidade foi atendida. O } \\
\text { componente pode ser representado pela questão: Meus motivos de visita à } \\
\text { cidade "x" foram plenamente atingidos? }\end{array}$ \\
\hline Prazer Intrínseco & $\begin{array}{l}\text { Revela em que extensão os sentidos do turista são gratificados. Questão- } \\
\text { exemplo: Em que medida a visita à cidade foi prazerosa, considerando todos os } \\
\text { sentidos? }\end{array}$ \\
\hline $\begin{array}{l}\text { Conformidade } \\
\text { com padrões }\end{array}$ & $\begin{array}{l}\text { Afere o quanto a cidade visitada é típica de sua categoria. Exemplo: A cidade } \\
\text { "x" é equivalente a outras similares em termos de turismo? }\end{array}$ \\
\hline Confirmação de & $\begin{array}{l}\text { Investiga se as expectativas que a pessoa tinha antes da visita foram atendidas. } \\
\text { Pode ser exemplificada pela questão: As minhas expectativas na visita a essa } \\
\text { cidade foram atendidas, superadas ou frustradas? }\end{array}$ \\
\hline Certeza & $\begin{array}{l}\text { Indica em que nível a pessoa está certa de que o destino turístico continuará a } \\
\text { ser uma boa alternativa em visitas futuras. Exemplo: O quão certo estou que } \\
\text { novas visitas a essa cidade serão interessantes no futuro? }\end{array}$ \\
\hline Agente & $\begin{array}{l}\text { Identifica o agente percebido como causador de um evento. A mudança do } \\
\text { agente pode modificar a experiência emocional. Exemplo: O que causou essa } \\
\text { experiência (positiva ou negativa) que tive na visita à cidade? }\end{array}$ \\
\hline Potencial de & $\begin{array}{l}\text { Indica o grau de facilidade com que a pessoa consegue lidar com adversidades } \\
\text { durante a estadia. Questão-exemplo: Consegui lidar com adversidades vividas } \\
\text { na cidade, quando a visitei? }\end{array}$ \\
\hline
\end{tabular}

Quadro 1: Componentes das avaliações (adaptado ao turismo de Tonetto e Desmet, 2012) 
As premissas do estudo foram que a experiência turística pode ser projetada a partir do design emocional e que a Teoria dos Appraisals é capaz de viabilizar uma análise proveitosa no referido contexto. Calcados nas referidas proposições, os objetivos da pesquisa foram: (a) avaliar os tipos de experiências emocionais experimentadas pelos turistas em suas cidades preferidas; e (b) relacionar as vivências identificadas às avaliações (appraisals) das pessoas. Os resultados permitirão compreender como é possível construir ambientes urbanos para estimular tais tipos de experiências.

A relevância do estudo, em nível aplicado, refere-se à potencial qualificação de projetos que visem a estimular experiências desejadas por turistas. Assim, torna-se relevante para profissionais que atuem em tais contextos. Em nível teórico, permitirá o avanço do conhecimento sobre as relações entre território e experiência emocional, em uma perspectiva relacional entre arquitetura, design e psicologia das emoções (Teoria dos Appraisals).

A fim de melhor compreender, em nível teórico, a relação entre turistas e o território, a seção seguinte desenvolve as bases da relação entre o ambiente construído e o turismo. Posteriormente, são apresentados o método, os resultados e sua discussão.

\section{O ambiente construído e o turismo}

Embora tenha se consolidado nos países desenvolvidos após a Segunda Guerra Mundial, a indústria do turismo foi solidificada mundialmente apenas nos anos 1980 e 1990. Tal processo foi alancado pelos avanços da globalização, da aviação comercial e da navegação marítima, acirrando a competitividade entre os destinos. Nesse cenário, muitas cidades representam lugares articulados para cultivar o turismo, constituindo-se como centros urbanos que descobriram uma importante fonte de renda e desenvolvimento social (MORGAN, PRITCHARD E PRIDE, 2007).

Para Nadal (2017), o turismo é um fenômeno social do século XX que tende a aumentar no século XXI. Segundo o autor, mais de $11 \%$ da humanidade vive de atividades na área, sendo que, em algumas regiões, ele chega a representar até $50 \%$ do PIB. No entanto, não é apenas um negócio, visto que esses movimentos de massas implicam, também, em intercâmbio 
de ideias, projetos, mestiçagens e paz. No entanto, atividades descontrolas podem interferir negativamente na cultura local.

Ressalta-se, nessa direção, a responsabilidade dos gestores no equilíbrio entre as demandas locais e do turismo. No caso do Butão, por exemplo, que representa uma porta de entrada para o Himalaia, busca-se controlar o fluxo, as ações e o número de visitantes. Todos precisam entrar no País por meio de uma agência autorizada, que organiza transporte, guia e alojamento.

$\mathrm{Na}$ lógica de equilíbrio, sabe-se que o turismo gera riquezas, mas comumente exige uma transformação urbanística nas cidades. Há necessidade de construções eminentemente turísticas (como hotéis, apartamentos, vilas, chalés, restaurantes, discotecas, etc.), empreendimentos para serviços (comércios, estabelecimentos bancários e de seguros, clínicas e postos de assistência médica, igrejas, escritórios municipais, etc.), assim como moradia para prestadores de serviços. Além da infraestrutura, atividades e outros atrativos são projetados, visando a proporcionar experiências memoráveis aos visitantes (KOTLER, REIDER E HEIN, 1993).

Algumas cidades construíram suas próprias atrações para estimular o turismo local. Um exemplo é Orlando, a cidade mais visitada dos Estados Unidos. O destino é famoso por suas atrações de entretenimento, que inclui os parques Walt Disney World Resort, Universal Orlando Resort e SeaWorld Orlando (ver Figura 1). Em 2015, recebeu mais de 55 milhões de turistas, o que exige organizar uma imensa infraestrutura de hotéis, carros de passeio e guias. Possui 100 mil quartos de hotéis à disposição e 26 mil residências de aluguel para passar férias, empregando 230 mil pessoas na região.
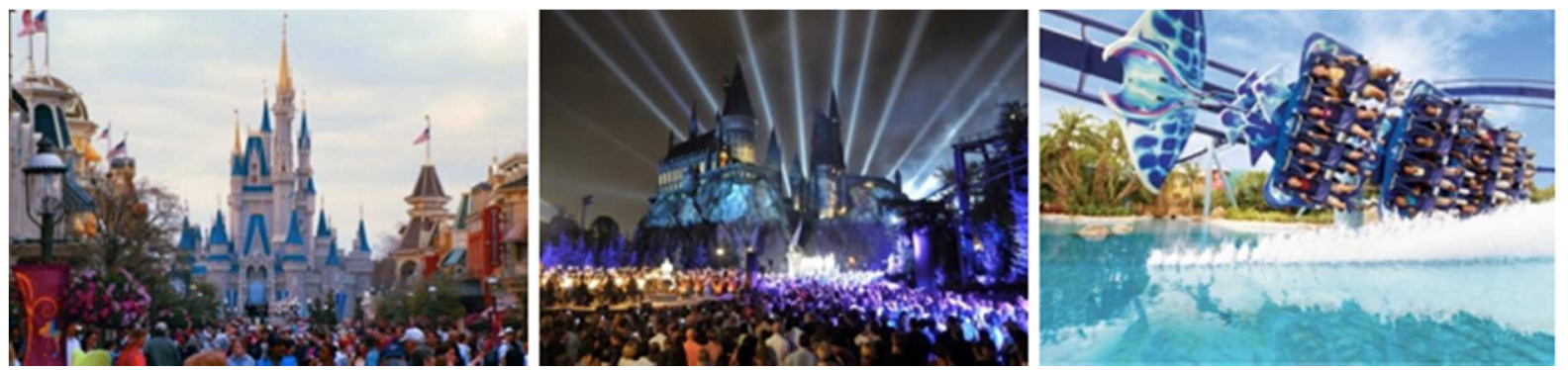

Figura 1 - Parque Disney World - Fonte: https://disneyworld.disney.go.com/ 
A Figura 1 demonstra a artificialidade dos atrativos de Orlando, o que indica intervenção humana extrema. Não é raro, nesse sentido, que o turismo intenso e mal planejado ocasione danos severos ao local que o proporciona. Por mais que sejam observadas medidas para a preservação do Patrimônio Histórico, Arquitetônico e Cultural, constata-se, também, a contínua destruição de monumentos para conforto, diminuição dos custos de manutenção e valorização imobiliária.

Além do turismo tradicional, observa-se a realização de megaeventos efêmeros, como a Copa do Mundo de Futebol, os Jogos Olímpicos e as corridas de Fórmula 1, ou, ainda, eventos culturais, como turnês de shows, feiras internacionais e festas populares. Tais eventos deixam dois tipos de legados para seus organizadores: os tangíveis (infraestrutura construída) e os intangíveis (impacto cultural). Em ambos os casos, podem ser benéficos ou danosos, apesar de o desenvolvimento ser tendencioso em relação a grandes organizações esportivas, como a FIFA. Segundo Coakley e Souza (2015), o suposto legado favorece essas instituições, em detrimento de melhorias que privilegiem a população.
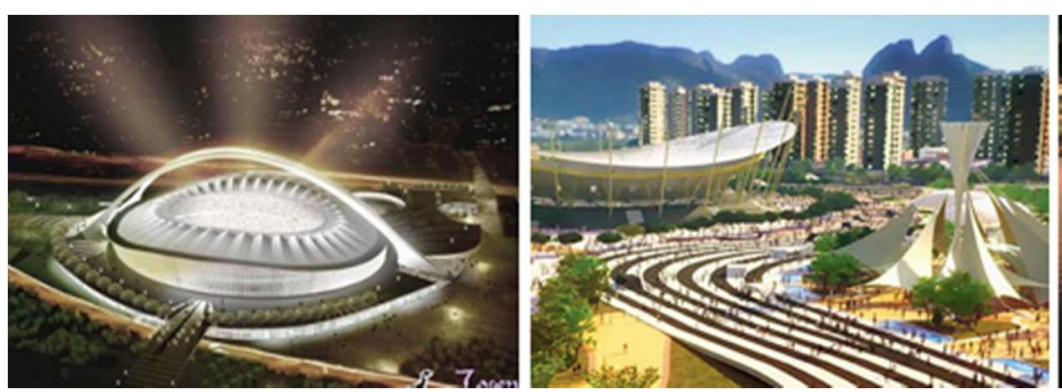

Figura 2 - Transformações urbanísticas (Projeto Rio 2016, Jogos Olímpicos)

Fonte: www.rio2016.org

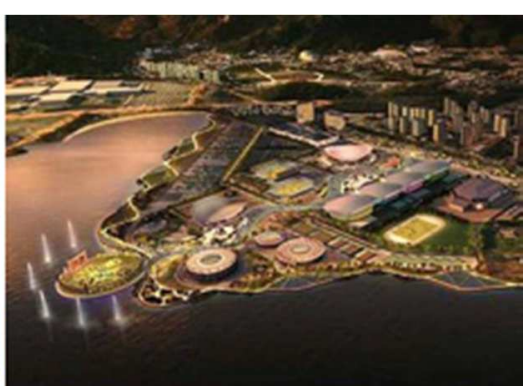


do tango na cidade de Buenos Aires (SAVIGLIANO, 2005). Essas atividades culturais são, assim, concebidas como uma forma alternativa de turismo, em que elementos locais passam a ser evidenciados, conduzindo a novas formas de interpretar a autenticidade dos destinos (TALAVERA, 2003).

Da mesma forma que a exploração local pode ser negativa, ela também pode ser um importante atrativo. Elementos culturais configuram os aspectos únicos dos lugares, que podem ser essenciais em contextos nos quais é observada grande similaridade de produtos no turismo, já que muitos destinos oferecerem bons serviços, instalações e atributos, como águas azuis, sol, povo amigável, excelentes resorts, hotéis e atrações (MORGAN, PRITCHARD e PIGGOTT, 2002). Portanto, se os benefícios são percebidos como equivalentes, o turista pode buscar lugares fora do comum ou que ofereçam prazeres inusitados.

As ideias de identidade e de diferença dependem do contexto cultural, defende Queluz (2008), pois um signo só existe em contraposição a outros. A identidade brasileira, por exemplo, só faz sentido como conceito em suas discrepâncias em relação aos demais países. Assim, ela não pode ser compreendida fora do processo de produção simbólica e discursiva.

Nessa perspectiva, na busca por oferecer atrativos para os turistas, existem novamente exemplos de intervenções extremas em alguns dos principais destinos mundiais. É o caso da cidade de Las Vegas (Estados Unidos). Há de tudo lá, incluindo hotéis-cassino em construções gigantescas, cada uma explorando temáticas e identidades que nem sempre dialogam entre si. Segundo Silva (2014, p.379), Las Vegas é "a melhor síntese dos espaços urbanos contemporâneos norte-americanos, seja no que toca ao urbanismo espetáculo, com cenários temáticos de dimensões hiperbólicas em ambientes altamente densos, seja na imensidão da sua suburbanização dispersa". Ainda que a referida cidade represente um processo de urbanização questionado por muitos, sua artificialidade novamente é considerada atrativo por muitos.

Assim, um território pode ocupar um espaço diferenciado na mente do turista, na medida em que se afirma como um lugar que oferece algo que extrapola o ordinário. Apenas assim será capaz de estabelecer uma relação emocional com os visitantes a ponto de se tornar o destino preferido deles. Como não se pode experimentar o destino fisicamente antes de visitá-lo, os atributos do lugar são de difícil verificação e comparação, pois a escolha envolve 
riscos elevados: dispêndio financeiro e de tempo; expectativas de satisfação de necessidades psicológicas; e busca de status, de autoexpressão e de envolvimento social (SWARBROOKE; HORNER, 2002).

Para Tasci e Kozak (2006), existe a ativação da imagem de um lugar na mente das pessoas, ainda que seja através da simples pronúncia de seu nome. Esse processo ocorre mesmo no caso em que não existam atividades conscientes e organizadas de gestão da imagem. Com esse desafio, nas últimas três décadas, as cidades turísticas têm direcionado seus esforços para afirmar e reforçar a sua imagem. Para tanto, tomam como base a análise das condicionantes do mercado, como qualidade de vida e responsabilidade ambiental, desenvolvimento de tecnologias de informação e comunicação, economia das cidades, ativos físicos, entre outros. Assim, visam a potencializar e promover as suas principais características (KOTLER et al., 1999; AAKER e JOANCHIMSTHALER, 1997; ELIZAGARATE, 2003).

A preocupação em considerar a experiência das pessoas no desenvolvimento de projetos tem se revelado um tópico de interesse e pesquisa na área (REIS, 1997). Desde então, diversos estudos têm focado em perspectivas metodológicas da participação do usuário na definição de critérios projetuais (ANDRADE, 2002) e em aspectos cognitivos das avaliações que fazem sobre sua qualidade (REIS e LAY, 2006; RHEINGANTZ e ALCANTARA, 2007). Seguindo a linha de investigação da cognição, mas, neste caso, com foco também nos aspectos emocionais, apresenta-se, a seguir, o método de pesquisa utilizado.

\section{Método}

Os objetivos da pesquisa foram investigar os tipos de experiências emocionais vividas nas cidades preferidas pelos turistas e relacioná-las a suas avaliações, seguindo o modelo proposto na Teoria dos Appraisals. Nessa direção, delineou-se um questionário, que foi aplicado na modalidade online, através de um link enviado por e-mail aos integrantes da rede de contatos dos pesquisadores. 
A amostra $(\mathrm{N}=310)$ foi composta por $59,68 \%$ de mulheres e $40,32 \%$ de homens com idade média de 31,14 anos (desvio padrão 9,57 anos). Todos os respondentes declararam escolaridade como Ensino Médio ou Ensino Superior completos.

Após clicar no link, inicialmente, o respondente deveria responder à pergunta "Qual é a sua cidade preferida para visitar?" Não importava qual cidade responderia, já que a pergunta apenas tinha como objetivo indicar que a pessoa deveria responder a todas as questões com base em uma única cidade.

Em seguida, os tipos de experiências com essas cidades foram avaliados, utilizando uma lista de palavras emocionais elaborada por Scherer (2005). Considerando o objetivo de mapear as relações das pessoas com cidades turísticas, o foco da pesquisa foi investigar apenas emoções positivas.

A lista de Scherer (2005) inclui as experiências de admiração, divertimento, ficar tocado(a), compaixão, contentamento, sentimento bom, gratidão, felicidade, esperança, humildade, interesse/entusiasmo, alegria, saudade, luxúria, prazer, orgulho, alívio, relaxamento/serenidade, surpresa e positividade. Originalmente publicada no idioma inglês, a listagem foi traduzida por Santos (2013), utilizando o procedimento de backtranslation, o que reforça sua adequação ao português.

O participante deveria, ainda segundo momento de pesquisa, indicar seu grau de concordância em relação ao fato de ter experimentado cada uma das emoções listadas em sua visita à cidade. A questão foi apresentada como segue:

Marque seu grau de concordância em relação a ter experimentado as seguintes emoções ao visitar a cidade. Atenção em relação a dois pontos!

1) Seja crítico(a) e marque as emoções que realmente experimentou ao visitar a cidade. Pode ser difícil, mas evite concordar com todas de forma automática apenas por gostar da cidade.

2) Discordar que tem uma emoção não significa que você sente o contrário. Discordar significa apenas que você não teve tal emoção.

Quando visito essa cidade, eu sinto/experimento...

Quadro 2 - Questão apresentada para mensuração da experiência emocional

As opções foram discordo totalmente (1), discordo em parte (2), não concordo nem discordo (3), concordo em parte (4) e concordo totalmente (5). "Não sei responder" também foi uma alternativa, o que possibilitou a exclusão de questionários incompletos.

Por fim, para a mensuração das avaliações, apresentou-se a questão "Manifeste seu grau de concordância em relação às afirmações abaixo", e a escala foi a mesma da questão anterior. 
As afirmativas (coluna central do Quadro 3) foram geradas com base na Teoria dos Appraisals e são referentes aos sete componentes propostos por Demir et al. (2009), conforme é possível observar no quadro a seguir. Apresenta-se, ainda, uma justificativa de adequação de cada uma ao modelo de pesquisa apresentada neste artigo.

\begin{tabular}{|c|c|c|}
\hline $\begin{array}{l}\text { Componente(s) } \\
\text { das Avaliações }\end{array}$ & $\begin{array}{l}\text { Frase(s) correspondente(s) no } \\
\text { instrumento de pesquisa }\end{array}$ & $\begin{array}{c}\text { Justificativa da adequação da frase } \\
\text { ao modelo teórico }\end{array}$ \\
\hline $\begin{array}{l}\text { Consistência do } \\
\text { Motivo }\end{array}$ & $\begin{array}{l}\text { O que me motiva a visitar essa cidade } \\
\text { é plenamente atendido quando estou } \\
\text { nela. }\end{array}$ & $\begin{array}{l}\text { O elemento central do motivo é ter } \\
\text { as demandas da pessoa atendidas. }\end{array}$ \\
\hline \multirow[t]{5}{*}{ Prazer Intrínseco } & $\begin{array}{l}\text { Visitar essa cidade é visualmente } \\
\text { prazeroso para mim (estar lá é } \\
\text { agradável para os olhos). }\end{array}$ & \multirow{5}{*}{$\begin{array}{l}\text { O prazer intrínseco foi desdobrado } \\
\text { em cinco sentidos, de modo que } \\
\text { fosse possível ter medidas isoladas } \\
\text { da contribuição de cada um para a } \\
\text { experiência do usuário. }\end{array}$} \\
\hline & $\begin{array}{l}\text { Em minha opinião, os sons dessa } \\
\text { cidade são prazerosos (estar lá é } \\
\text { agradável para os ouvidos). }\end{array}$ & \\
\hline & $\begin{array}{l}\text { Os odores nessa cidade são prazerosos } \\
\text { para mim (estar lá é agradável para o } \\
\text { olfato). }\end{array}$ & \\
\hline & $\begin{array}{l}\text { Para o meu paladar, os sabores da } \\
\text { culinária local são prazerosos nessa } \\
\text { cidade (estar lá é agradável para o } \\
\text { paladar). }\end{array}$ & \\
\hline & $\begin{array}{l}\text { As sensações corporais que tenho } \\
\text { nessa cidade são prazerosas (estar lá é } \\
\text { agradável para o corpo). }\end{array}$ & \\
\hline $\begin{array}{l}\text { Conformidade } \\
\text { com Padrões }\end{array}$ & $\begin{array}{l}\text { Acredito que essa cidade é semelhante } \\
\text { a outras equivalentes em termos de } \\
\text { turismo. }\end{array}$ & $\begin{array}{l}\text { A conformidade com padrões exige } \\
\text { comparação a outras opções } \\
\text { equivalentes. }\end{array}$ \\
\hline $\begin{array}{l}\text { Confirmação de } \\
\text { Expectativas }\end{array}$ & $\begin{array}{l}\text { Essa cidade superou as expectativas } \\
\text { que eu tinha antes de ir pela primeira } \\
\text { vez. }\end{array}$ & $\begin{array}{l}\text { Experiências positivas comumente } \\
\text { são associadas à superação do que } \\
\text { se esperava. }\end{array}$ \\
\hline Certeza & $\begin{array}{l}\text { Tenho certeza de que visitar essa } \\
\text { cidade continuará sendo uma ótima } \\
\text { opção de turismo para mim no futuro. }\end{array}$ & $\begin{array}{l}\text { O componente de certeza deve } \\
\text { expressar a visão do usuário em } \\
\text { relação à cidade e seu efeito sobre } \\
\text { ele no futuro. }\end{array}$ \\
\hline \multirow[t]{3}{*}{ Agente } & $\begin{array}{l}\text { A cidade em si é a uma grande atração } \\
\text { para mim. }\end{array}$ & \multirow{3}{*}{$\begin{array}{l}\text { Os agentes podem ser três: o } \\
\text { estímulo em si (a cidade), as } \\
\text { atividades desenvolvidas nele / com } \\
\text { ele e os eventos que ocorrem } \\
\text { independente do observador. Por } \\
\text { este motivo, optou-se por mensurá- } \\
\text { los separadamente. }\end{array}$} \\
\hline & $\begin{array}{l}\text { As coisas que eu posso fazer na cidade } \\
\text { são uma grande atração. }\end{array}$ & \\
\hline & $\begin{array}{l}\text { Os acontecimentos que se dão na } \\
\text { cidade são uma grande atração em } \\
\text { minha opinião. }\end{array}$ & \\
\hline $\begin{array}{l}\text { Potencial de } \\
\text { Coping }\end{array}$ & $\begin{array}{l}\text { É fácil lidar com adversidades que eu } \\
\text { viva / dificuldades que eu tenha como } \\
\text { turista quando estou nessa cidade. }\end{array}$ & $\begin{array}{l}\text { Este componente é referente à } \\
\text { capacidade percebida pela pessoa } \\
\text { de enfrentamento de adversidades. }\end{array}$ \\
\hline
\end{tabular}

Quadro 3 - Mensuração das avaliações na pesquisa 
As análises foram realizadas através do Statistical Package for the Social Sciences (SPSS). Utilizou-se a estatística descritiva para avaliar o quanto as pessoas concordaram em ter experimentado cada emoção listada na visita à cidade escolhida. Em seguida, a análise fatorial possibilitou a redução das 20 palavras emocionais a fatores, aqui denominados "tipos de experiências emocionais", em correspondência com os objetivos da pesquisa.

A estatística descritiva também foi aplicada à concordância com as frases que expressam as avaliações das pessoas em relação às cidades. Em seguida, buscou-se correlacionar as concordâncias entre (a) as frases e (b) ter experimentado cada tipo de experiência emocional $^{1}$, a fim de compreender, com base nas avaliações, como seria possível projetar cidades com potencial para despertar cada tipo de vivência extraída na análise fatorial.

A seguir, na seção 4, os resultados são apresentados. No capítulo 5, a seguir, os dados são discutidos em articulação com os conteúdos abordados na seção 2 .

\section{Apresentação dos resultados}

\subsection{Resultados da análise dos termos emocionais de Scherer e dos tipos de experiência}

O Gráfico 1 apresenta as médias e desvios padrão da concordância dos participantes em terem experimentado cada emoção descrita na visita a suas cidades turísticas favoritas.

Conforme é possível observar, as palavras emocionais com médias de concordância mais altas são alegria $(M=4,65 ; D P=0,65)$, interesse / entusiasmo $(M=4,59 ; D P=0,87)$, sentimento bom ( $M=4,58 ; D P=0,82)$ e felicidade $(M=4,57 ; D P=0,83)$. Como o objetivo da pesquisa foi identificar os tipos de experiência emocional vividos pelas pessoas em seus destinos turísticos preferidos, não emoções isoladas, a sequência ao tratamento dos dados deu-se através da análise fatorial.

\footnotetext{
${ }_{1}$ Para possibilitar essa análise, foi necessário gerar novas variáveis baseadas nos fatores extraídos a partir das 20 palavras emocionais de Scherer (2005). Cada fator gerou uma nova variável, e todas as palavras de cada fator foram utilizadas para calcular uma média do turista para cada tipo de experiência.
} 


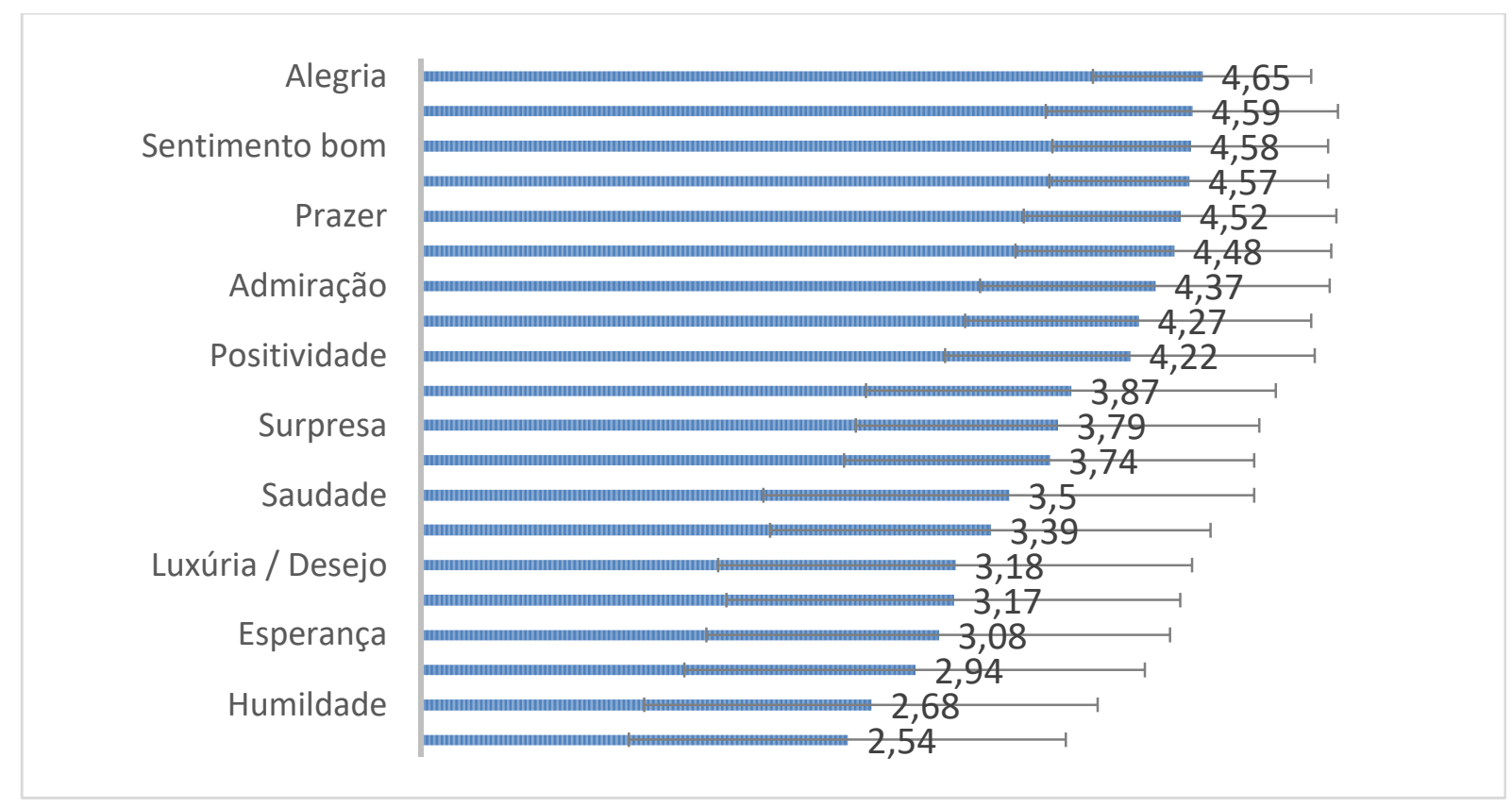

Gráfico 1 - Médias (decrescentes) da concordância de experimentação de cada emoção ( $N=310)$

A análise fatorial possibilitou a redução dos 20 termos emocionais de Scherer (2005) a cinco fatores, ou seja, grupos de emoções que tendem a ocorrer em conjunto. As emoções agrupadas, considerando suas cargas fatoriais, podem ser observadas na Tabela 1.

Vale ressaltar que os cinco fatores têm um papel importante para explicar a variância total dos dados da pesquisa. Entre eles, o que mais explica os resultados contribuiu com 13,15\% (Fator 1) e o que menos acrescenta foi responsável por 7,21\% da variância total (Fator 5). Os fatores representam $53,25 \%$ da variância total. 


\begin{tabular}{l|l|r}
\hline \multicolumn{1}{c|}{ Fator e Variância Explicada } & Palavras emocionais agrupadas & Cargas Fatoriais \\
\hline Fator 1: Altruísmo/Solidariedade & Alívio & 0,716 \\
\cline { 2 - 3 } Variância Explicada: 13,15\% & Humildade & 0,710 \\
\cline { 2 - 3 } & Esperança & 0,653 \\
\cline { 2 - 3 } & Compaixão & 0,571 \\
\cline { 2 - 3 } & Gratidão & 0,554 \\
\cline { 2 - 3 } & Relaxamento / Serenidade & 0,479 \\
\hline \multirow{2}{*}{$\begin{array}{l}\text { Fator 2: Diversão } \\
\text { Variância Explicada: 12,84\% }\end{array}$} & Divertimento & 0,716 \\
\cline { 2 - 3 } & Admiração & 0,714 \\
\cline { 2 - 3 } & Interesse / Entusiasmo & 0,672 \\
\cline { 2 - 3 } & Sentimento bom & 0,521 \\
\cline { 2 - 3 } & Positividade & 0,447 \\
\hline Fator 3: Alegria & Alegria & 0,808 \\
\cline { 2 - 3 } & Felicidade & 0,775 \\
\cline { 2 - 3 } & Prazer & 0,581 \\
\hline Fator 4: Vínculo com o território & Orgulho & 0,657 \\
\cline { 2 - 3 } Variância Explicada: 7,67\% & Saudade & 0,575 \\
\cline { 2 - 3 } & Luxúria / Desejo & 0,523 \\
\hline Fator 5: Quebra de expectativas & Fico tocado(a) & 0,666 \\
\cline { 2 - 3 } Variância Explicada: 7,21\% & Contentamento & 0,580 \\
\cline { 2 - 3 } & Surpresa & 0,507 \\
\hline
\end{tabular}

Tabela 1 - Matriz de componentes rotacionados: fatores, termos emocionais e cargas fatoriais

Foram calculadas as comunalidades das palavras emocionais. Os valores indicam a contribuição de cada termo para a variância total (BISQUERA, SARRIERA E MARTíNEZ, 2004). A média foi 0,53 , indicando que os componentes extraídos representam bem as variáveis. Todos os itens têm uma comunalidade entre 0,41 e 0,70, o que mostra que os 20 itens são consistentes para a pesquisa.

\subsection{Avaliações dos pesquisados e suas relações com os tipos de experiência emocional}

A Tabela 2, a seguir, apresenta as médias e desvios padrão das avaliações dos participantes em relação a suas cidades turísticas preferidas. 


\begin{tabular}{|c|c|c|c|}
\hline $\begin{array}{l}\text { Componente } \\
\text { de Avaliação }\end{array}$ & Afirmação & Média & $\begin{array}{l}\text { Desvio } \\
\text { Padrão }\end{array}$ \\
\hline $\begin{array}{l}\text { Consistência do } \\
\text { Motivo }\end{array}$ & $\begin{array}{l}\text { O que me motiva a visitar essa cidade é plenamente } \\
\text { atendido quando estou nela. }\end{array}$ & 4,41 & 0,99 \\
\hline \multirow[t]{5}{*}{ Prazer Intrínseco } & $\begin{array}{l}\text { Visitar essa cidade é visualmente prazeroso para mim (estar } \\
\text { lá é agradável para os olhos). }\end{array}$ & 4,83 & 0,49 \\
\hline & $\begin{array}{l}\text { Na minha opinião, os sons dessa cidade são prazerosos } \\
\text { (estar lá é agradável para os ouvidos). }\end{array}$ & 3,61 & 1,28 \\
\hline & $\begin{array}{l}\text { Os odores nessa cidade são prazerosos para mim (estar lá é } \\
\text { agradável para o olfato). }\end{array}$ & 3,25 & 1,38 \\
\hline & $\begin{array}{l}\text { Para o meu paladar, os sabores da culinária local são } \\
\text { prazerosos nessa cidade (estar lá é agradável para o } \\
\text { paladar). }\end{array}$ & 4,26 & 1,18 \\
\hline & $\begin{array}{l}\text { As sensações corporais que tenho nessa cidade são } \\
\text { prazerosas (estar lá é agradável para o corpo). }\end{array}$ & 4,17 & 1,18 \\
\hline $\begin{array}{l}\text { Conformidade } \\
\text { com padrões }\end{array}$ & $\begin{array}{l}\text { Acredito que essa cidade é semelhante a outras } \\
\text { equivalentes em termos de turismo. }\end{array}$ & 3,03 & 1,36 \\
\hline $\begin{array}{l}\text { Confirmação de } \\
\text { Expectativas }\end{array}$ & $\begin{array}{l}\text { Essa cidade superou as expectativas que eu tinha antes de ir } \\
\text { pela primeira vez. }\end{array}$ & 4,38 & 1,24 \\
\hline Certeza & $\begin{array}{l}\text { Tenho certeza de que visitar essa cidade continuará sendo } \\
\text { uma ótima opção de turismo para mim no futuro. }\end{array}$ & 4,73 & 0,74 \\
\hline \multirow[t]{3}{*}{ Agente } & A cidade em si é a uma grande atração para mim. & 4,67 & 0,84 \\
\hline & $\begin{array}{l}\text { As coisas que eu posso fazer na cidade são uma grande } \\
\text { atração. }\end{array}$ & 4,52 & 0,90 \\
\hline & $\begin{array}{l}\text { Os acontecimentos que se dão na cidade são uma grande } \\
\text { atração na minha opinião. }\end{array}$ & 4,17 & 1,16 \\
\hline $\begin{array}{l}\text { Potencial de } \\
\text { Enfrentamento }\end{array}$ & $\begin{array}{l}\text { É fácil lidar com adversidades que eu viva / dificuldades que } \\
\text { eu tenha como turista quando estou nessa cidade. }\end{array}$ & 3,93 & 1,26 \\
\hline
\end{tabular}

Tabela 2 - Avaliações em relação às cidades preferidas $(\mathrm{N}=310)$

Algumas avaliações parecem bastante responsáveis pela preferência por dada cidade, o que é saliente na observação das médias de concordância mais altas: "Visitar essa cidade é visualmente prazeroso para mim (estar lá é agradável para os olhos)" (M=4,83; $D P=0,49)-$ componente de prazer intrínseco na modalidade visual, "Tenho certeza de que visitar essa cidade continuará sendo uma ótima opção de turismo para mim no futuro" $(M=4,73$; $\mathrm{DP}=0,74)$ - componente de certeza, "A cidade em si é a uma grande atração para mim" $(M=4,67 ; D P=0,84)$ - componente de agência que representa a própria cidade (ou "o estímulo em si") e "As coisas que eu posso fazer na cidade são uma grande atração" $(M=4,52 ; D P=0,90)$ - componente de agência que indica o contexto de uso (ou seja, as atividades realizadas no local). 
A Tabela 3 correlaciona as médias de concordância das avaliações com as cinco novas variáveis (correspondentes aos cinco fatores extraídos na análise fatorial) criadas a partir das médias de experimentação de cada emoção listada.

\begin{tabular}{|c|c|c|c|c|c|c|}
\hline \multirow{2}{*}{$\begin{array}{c}\text { Componente de } \\
\text { Avaliação }\end{array}$} & \multirow{2}{*}{ Afirmação } & \multicolumn{5}{|c|}{ Fator } \\
\hline & & 1 & 2 & 3 & 4 & 5 \\
\hline $\begin{array}{l}\text { Consistência do } \\
\text { Motivo }\end{array}$ & $\begin{array}{l}\text { O que me motiva a visitar } \\
\text { essa cidade é plenamente } \\
\text { atendido quando estou nela. }\end{array}$ & 0,059 & $0,336^{* *}$ & $0,310^{* *}$ & $0,162^{* *}$ & $0,211^{* *}$ \\
\hline \multirow[t]{5}{*}{$\begin{array}{l}\text { Prazer } \\
\text { Intrínseco }\end{array}$} & $\begin{array}{l}\text { Visitar essa cidade é } \\
\text { visualmente prazeroso para } \\
\text { mim (estar lá é agradável } \\
\text { para os olhos). }\end{array}$ & 0,065 & $0,294^{* *}$ & $0,212^{* *}$ & 0,089 & $0,176^{* *}$ \\
\hline & $\begin{array}{l}\text { Em minha opinião, os sons } \\
\text { dessa cidade são prazerosos } \\
\text { (estar lá é agradável para os } \\
\text { ouvidos). }\end{array}$ & $0,294^{* *}$ & $0,155^{* *}$ & $0,146^{* *}$ & 0,045 & 0,109 \\
\hline & $\begin{array}{l}\text { Os odores nessa cidade são } \\
\text { prazerosos para mim (estar lá } \\
\text { é agradável para o olfato). }\end{array}$ & $0,332^{* *}$ & 0,065 & 0,015 & $0,121^{*}$ & $0,150^{* *}$ \\
\hline & $\begin{array}{l}\text { Para o meu paladar, os } \\
\text { sabores da culinária local são } \\
\text { prazerosos nessa cidade } \\
\text { (estar lá é agradável para o } \\
\text { paladar). }\end{array}$ & $0,166^{* *}$ & $0,125^{*}$ & 0,056 & $0,196^{* *}$ & $0,129^{*}$ \\
\hline & $\begin{array}{l}\text { As sensações corporais que } \\
\text { tenho nessa cidade são } \\
\text { prazerosas (estar lá é } \\
\text { agradável para o corpo). }\end{array}$ & $0,270^{* *}$ & $0,251^{* *}$ & $0,236^{* *}$ & $0,211^{* *}$ & $0,185^{* *}$ \\
\hline $\begin{array}{l}\text { Conformidade } \\
\text { com padrões }\end{array}$ & $\begin{array}{l}\text { Acredito que essa cidade é } \\
\text { semelhante a outras } \\
\text { equivalentes em termos de } \\
\text { turismo. }\end{array}$ & $0,122^{*}$ & 0,082 & 0,022 & 0,001 & $-0,037$ \\
\hline
\end{tabular}

Tabela 3 - Correlações entre os tipos de experiência emocional e as avaliações (continua) Observações: ${ }^{* *} p<0,01 ;{ }^{*} p<0,05$ - Fonte: Elaborado pelos autores. 


\begin{tabular}{|c|c|c|c|c|c|c|}
\hline \multirow{2}{*}{$\begin{array}{l}\text { Componente de } \\
\text { Avaliação }\end{array}$} & \multirow{2}{*}{ Afirmação } & \multicolumn{5}{|c|}{ Fator } \\
\hline & & 1 & 2 & 3 & 4 & 5 \\
\hline $\begin{array}{l}\text { Confirmação de } \\
\text { Expectativas }\end{array}$ & $\begin{array}{l}\text { Essa cidade superou as } \\
\text { expectativas que eu tinha } \\
\text { antes de ir pela primeira vez. }\end{array}$ & 0,099 & $0,272^{* *}$ & $0,209^{* *}$ & $0,128^{*}$ & $0,194^{* *}$ \\
\hline Certeza & $\begin{array}{l}\text { Tenho certeza de que visitar } \\
\text { essa cidade continuará sendo } \\
\text { uma ótima opção de turismo } \\
\text { para mim no futuro. }\end{array}$ & 0,044 & $0,285^{* *}$ & $0,243^{* *}$ & 0,111 & $0,155^{* *}$ \\
\hline Agente & $\begin{array}{l}\text { A cidade em si é a uma } \\
\text { grande atração para mim. }\end{array}$ & $-0,054$ & $0,242^{* *}$ & $0,207^{* *}$ & $0,143^{*}$ & $0,212^{* *}$ \\
\hline & $\begin{array}{l}\text { As coisas que eu posso fazer } \\
\text { na cidade são uma grande } \\
\text { atração. }\end{array}$ & $-0,037$ & $0,297^{* *}$ & $0,242^{* *}$ & $0,123^{*}$ & $0,137^{*}$ \\
\hline & $\begin{array}{l}\text { Oe acontecimentos que se } \\
\text { dão na cidade são uma } \\
\text { grande atração na minha } \\
\text { opinião. }\end{array}$ & 0,041 & $0,266^{* *}$ & $0,238^{* *}$ & $0,212^{* *}$ & $0,172^{* *}$ \\
\hline $\begin{array}{l}\text { Potencial de } \\
\text { Enfrentamento }\end{array}$ & $\begin{array}{l}\text { É fácil lidar com adversidades } \\
\text { que eu viva / dificuldades que } \\
\text { eu tenha como turista } \\
\text { quando estou nessa cidade. }\end{array}$ & 0,060 & $0,224^{* *}$ & $0,158^{* *}$ & $0,171^{* *}$ & 0,099 \\
\hline
\end{tabular}

Tabela 3 - Correlações entre os tipos de experiência emocional e as avaliações (continuação) Observações: ${ }^{* *} p<0,01 ;{ }^{*} p<0,05$ - Fonte: Elaborado pelos autores.

As análises de correlação indicam que cada tipo de experiência emocional detectado está relacionado a avaliações específicas, ou seja, seria possível desenvolver projetos em cidades com o potencial de reforçar cada vivência extraída na análise fatorial. Todas as correlações foram de ordem positiva, o que significa que, quanto mais presente a concordância em ter vivido dado tipo de experiência emocional, maior o assentimento em relação à(s) frase(s) apresentada(s) caracterizarem cada componente de avaliação. As correlações (Tabela 3) serão discutidas na seção seguinte.

\section{Discussão dos resultados}

A análise revelou cinco tipos de experiências emocionais vividas pelos turistas em suas cidades favoritas. Ao gerar médias de concordância em ter experimentado cada item da lista para cada fator (SCHERER, 2005), sob a forma de novas variáveis no banco de dados, foi 
possível correlacioná-las com as avaliações dos participantes (DESMET, 2002, DEMIR ET AL., 2009). Existe, portanto, um padrão de respostas presente em cada tipo de vivência, indicando estímulos que podem ser projetados através do design.

Como salientado por Tonetto, Tarouco e Greggianin (2015), estímulos turísticos podem ser naturais ou projetados. A própria paisagem urbana representa um atrativo (OLIVEIRA, ANJOS E LEITE, 2008), apesar de não ter sido o único fator saliente nos resultados, conforme se discute a seguir.

A experiência de altruísmo/solidariedade (Fator 1: alívio, humildade, esperança, compaixão, gratidão e relaxamento / serenidade) foi correlacionada com prazer intrínseco (auditivo, olfativo, gustativo e táctil) e conformidade com padrões. É interessante observar que a consistência do motivo apareceu para todos os tipos de experiência emocional, exceto para a experiência de altruísmo/solidariedade. Percebe-se, ainda, que o Fator 1 é o único relacionado com a conformidade com padrões (similaridade da cidade a outras), não vinculado à confirmação de expectativas e com nenhuma agência investigada (a cidade, atividades desempenhadas pela pessoa ou eventos independentes do turista). Assim, foi possível observar que não existem muitos elementos projetáveis a serem utilizados em design para estimular esse tipo de experiência, diferentemente de outros fatores. Possivelmente isso ocorreu em função de ser algo bastante motivado por elementos internos do turista, já que a explicação não está na cidade como agência da experiência positiva com o território.

O confronto com a realidade parece, portanto, ser uma experiência desejada por muitos, em consonância com o estudo de Freire-Medeiros (2007). É o caso do turismo solidário, cujo objetivo é conhecer um país, visitando os principais pontos de interesse, bem como colaborar com o trabalho desenvolvido por organizações não governamentais. Um exemplo é o projeto Afrique Aventure, mantido pela ONG espanhola Campamentos Solidarios, que tem como objetivo a criação de uma rede de acampamentos que cobrem as zonas mais necessitadas do Senegal (CAMPAMENTOS, 2015).

A experiência de altruísmo/solidariedade reforça uma forma de turismo não baseada em intervenções urbanas. Tem aparente base na cultura local e não na exploração, reforçando a visão de Nadal (2017) de que a atividade pode ser vista não apenas como negócio, mas 
também como intercâmbio de ideias e projetos. A relação com as riquezas simbólicas, nesse caso, ficou evidente, afastando-se da lógica de mero consumo (DA ROS e CRUZ, 2011).

Por outro lado, a experiência de diversão (Fator 2: divertimento, admiração, interesse/entusiasmo, sentimento bom e positividade) pareceu facilmente estimulada por projetos focados na cidade. Ela foi correlacionada com consistência do motivo, prazer intrínseco (visual, auditivo, gustativo e táctil), confirmação de expectativas (com superação), certeza, agente (a cidade em si, as atividades desenvolvidas nela e os acontecimentos independentes do observador) e potencial de enfrentamento. Por mais que a vivência de alegria (Fator 3: alegria, felicidade e prazer) possa parecer semelhante à anterior, a estimulação gustativa foi determinante para o delineamento de uma experiência diferenciada no Fator 2 em relação ao Fator 3, já que todas as demais correlações significativas são equivalentes.

Kotler (1993) indica que as atividades oferecidas aos turistas podem proporcionar experiências memoráveis, o que ficou saliente na discussão dos fatores 2 e 3 . Parece, nessa direção, que as experiências divertidas/alegres podem ser categorizadas em função da presença ou ausência de projetos de estimulação gastronômica, mas ambas necessitam de estímulos e eventos adequados para promoção dessas vivências positivas. Por mais que aparentemente lógica, a diferença indica que a escolha por uma cidade como a favorita é um processo muito diferenciado em função da gastronomia (no Fator 2) em relação a outras formas de prazer (Fator 3). Um território que é espontaneamente recordado como referência em alegria associada à comida é a Bahia, um estado Brasileiro que, além de explorar o slogan "Sorria, você está na Bahia", é também internacionalmente conhecido pela tradicional culinária típica. Alimentação e cultura andam de mãos dadas, proporcionando uma imersão nos grupos locais (TALAVERA, 2003).

Os tipos de experiência definidos como alegria e diversão podem ser vinculados a intervenções urbanas, incluindo a possibilidade de reforço dos atrativos locais, respeitando os habitantes, ou a modalidade extrema, como no caso da cidade norte-americana Las Vegas (SILVA, 2014). Trata-se de uma forma de turismo que estimula a movimentação de pessoas, bem como o desenvolvimento econômico dos visitados. No entanto, é preciso chamar a atenção dos profissionais da área para os perigos da urbanização descontrolada. 
Já o vínculo com o território (Fator 4: orgulho, saudade e luxúria / desejo) foi uma experiência correlacionada com consistência do motivo, prazer intrínseco (olfativo, gustativo e táctil), confirmação de expectativas (com superação), agente (a cidade em si, as atividades desenvolvidas nela e os acontecimentos independentes do observador) e potencial de enfrentamento. A natureza das emoções agrupadas indica, assim como no Fator 1, que a conexão com o outro e consigo não seria facilmente projetável pelo design, ao contrário das experiências dos fatores 2 e 3. No entanto, a cidade foi reconhecida como agente da vivência positiva. Esse fato demonstra que saudade e desejo são advindos de estímulos que ocorrem em uma cidade específica e que não são passíveis de serem reproduzidos. Dessa forma, projetos que tomem como base características territoriais diferenciais podem ser um importante caminho para estabelecer tais vínculos.

Da Ros e Cruz (2011) apontam, em uma perspectiva crítica, que esse tipo de atividade pode estimular relações com as riquezas do lugar, tratando-as, muitas vezes, como objetos de consumo. Pode ser o caso, por exemplo, de um pedido de casamento feito na Torre Eiffel, com Paris (França) ao fundo e um sol se pondo no horizonte. Representa, portanto, uma experiência impossível de ser reproduzida com a mesma intensidade em outro local.

Nessa direção, o vínculo com o território pode facilmente ser uma experiência de valorização local ou enveredar para o turismo de exploração, especialmente considerando o papel da cidade em si como agente da vivência positiva. Um megaevento de futebol no Rio de Janeiro (Brasil), para um torcedor inveterado, por exemplo, pode despertar preferências por um território, associando sol, praia e esportes. Assim, o turismo pode ser visto como uma oportunidade de desenvolvimento ou como um motivador de obras de infraestrutura que favorecem mais as instituições envolvidas que a população (COAKLEY e SOUZA, 2015).

Por fim, a experiência de quebra de expectativas (Fator 5: fico tocado, contentamento e surpresa) foi relacionada a consistência do motivo, prazer intrínseco (visual, olfativo, gustativo e táctil), confirmação de expectativas (com superação) e agente (a cidade em si, as atividades desenvolvidas nela e os acontecimentos independentes do observador). No Fator 5, destaca-se a presença de superação de expectativas e a inexistência de correlação com o potencial de enfrentamento. Tal combinação indica que as pessoas podem viver desafios difíceis de vencer, mas que as dificuldades e sua superação não as impedem de ter uma surpresa positiva com o local. Assim, pode-se projetar desafios de ordem cultural ou 
acadêmica, por exemplo, o que deverá proporcionar a experiência de superação. Facilidade, aqui, não é sinônimo de preferência.

O caso da quebra de expectativas demonstra a relevância de buscar o que não é usual, evitando a paridade indicada por Morgan, Pritchard e Piggott (2002). O turismo radical é um dos exemplos mais apropriados para este tipo de experiência, pois, além da contemplação da paisagem envolvida, carrega junto a satisfação presente na superação de um desafio ou em uma meta atingida. Trata-se de uma sensação percebida entre alpinistas e aventureiros, que, ao chegar ao topo de uma montanha ou a um lugar inexplorado (e até inóspito), fincam suas bandeiras e comemoram a "conquista" de mais um território.

Cidade e natureza podem ser vistas de forma integrada, valorizando uma forma de turismo que não é baseada em exploração. Ao invés da paisagem artificial de Orlando ou Las Vegas (Estados Unidos), outras cidades, como Queenstown (Nova Zelândia), integram o espaço urbano ao natural (Figura 3).

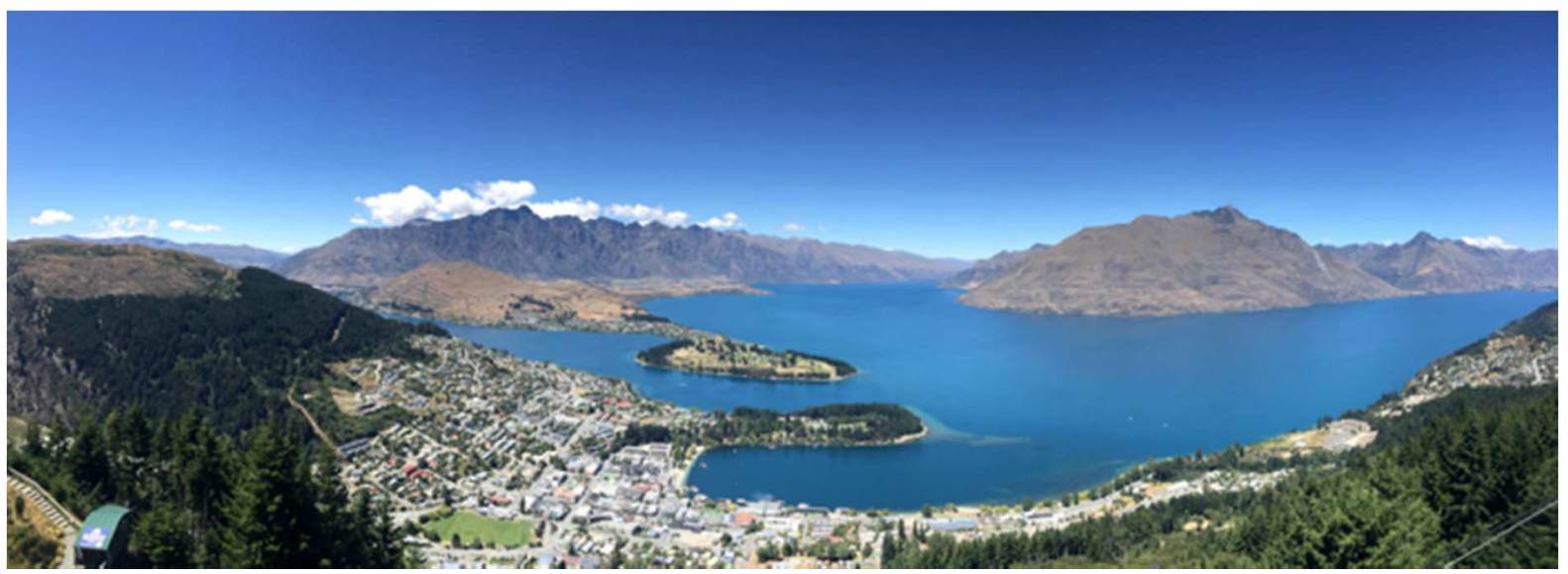

Figura 3: Vista aérea de Queenstown (Nova Zelândia) da Ben Lomond Scenic Reserve Fonte: Acervo pessoal do autor.

Como consideração geral, vale indicar que a estimulação sensorial está presente como um fator determinante dos cinco tipos de experiência. À exceção das sensações corporais, no entanto, cada vivência mapeada tem uma fórmula distinta em termos de prazer intrínseco. 


\section{Considerações finais}

Os objetivos da pesquisa foram avaliar os tipos de emoções vividas por turistas em suas cidades preferidas e relacioná-las às avaliações dos participantes. Para realizar o estudo, a Teoria dos Appraisals mostrou-se um importante viabilizador do método, indicando seu potencial para investigações sobre emoções e design de experiências turísticas.

Através do método proposto, percebeu-se que existem cinco tipos de experiências emocionais comumente vividas que influenciam a preferência por uma cidade: altruísmo/solidariedade, diversão, alegria, vínculo com o território e quebra de expectativas. Em muitos casos, como visto na seção anterior, é possível projetar estímulos que auxiliem a proporcionar essas vivências às pessoas.

Nessa direção, a principal contribuição do estudo foi demonstrar que é possível desenvolver estímulos com potencial para despertar as experiências desejadas pelas pessoas. No entanto, muitos elementos não podem ser projetados apenas com base no ambiente construído, como o caso dos estilos gastronômicos. É possível, ainda assim, realizar intervenções para sua valorização.

Os tipos de experiência visivelmente mais relacionados a modificações urbanas extremas foram alegria e diversão. Vale ressaltar que realizar projetos que viabilizem e fomentem a atividade turística não têm, necessariamente, viés negativo. As intervenções podem reforçar aspectos locais e incentivar a economia, sem caracterizar a interferências danosa do território. Acredita-se que a pesquisa, nessa direção, tenha evidenciado o caráter benéfico com que as emoções podem atrair as pessoas, ficando a cargo dos profissionais a escolha entre a busca de valorização positiva dessas vivências ou a exploração perversa das cidades.

Por outro lado, as demais formas de turismo baseadas em experiências emocionais não foram tão fortemente conectadas a potenciais interferências negativas na cidade. Esse dado mostra que existem oportunidades de lançar mão do fomento a diversas atividades no âmbito econômico sem perder a humanidade necessária para o desenvolvimento sustentável das cidades. 
Tratou-se de um estudo realizado com brasileiros. Evidentemente, diferenças culturais poderão impactar os resultados, de modo que existe, nesse ponto, uma importante oportunidade para a realização de estudos interculturais.

Outra limitação importante foi o método. Apesar das análises terem revelado dados consistentes, o uso da lista de emoções de Scherer (2005) certamente influenciou os resultados do estudo. A aplicação de técnicas de pesquisa complementares aponta para o desenvolvimento de estudos futuros na área.

Por fim, vale ressaltar limitações que extrapolam o método, bem como direcionamentos para uma agenda de pesquisa futura. Conforme destacado na introdução, a experiência efêmera de alguns não pode ser considerada de forma descolada da realidade local. Projetos que visem a qualificar as vivências dos turistas necessitam considerar a adequação das propostas às características de cada cidade, dos estilos de vida dos moradores, de fatores socioambientais e culturais, entre tantos outros. Como impacto final desejado, é determinante que se possa qualificar as atividades daqueles que transitam temporariamente na cidade, mas com respeito e legado para aqueles que lá estão e ficarão. Nessa direção, outro estudo futuro poderia residir na mediação entre emoções desejadas pelos visitantes e diferentes realidades locais, a fim de fomentar o desenvolvimento sustentável do turismo.

\section{Referências bibliográficas}

AAKER, D.A. and JOACHIMSTHALER, E. Como construir marcas líderes. Porto Alegre : Bookman. 2007.

ANDRADE, C.M. Aspectos metodológicos relacionados à participação do usuário na definição de critérios de projeto : o caso da Editora Abril em São Paulo. Ambiente Construído, 2002, vol. 2, № 3), p. 57-70.

BISQUERRA, R., Sarriera, J.C. and Martínez, F. Introdução à estatística: enfoque informático com o pacote estatístico SPSS. Porto Alegre : ArtMed. 2004.

CAMPAMENTOS SOLIDARIOS. ¿Qué es "Afrique aventure"? Disponível em: http://www.campamentossolidarios.org/index.php?page=quienes-afrique Consulta em 24 jun. 2015.

COAKLEY, J. and SOUZA, D.L. Legados de megaeventos esportivos : considerações a partir de uma perspectiva crítica. Revista Brasileira de Educação Física e Esporte, 2015, vol. 29, no 4, p. 675-686.

DA ROS, J.P. and CRUZ, W.F.O. Memórias do lugar : o turismo na ilha do Campeche. Psicologia \& Sociedade, 2011, vol. 23, no 3, p. 625-633. 
DEMIR, E., DESMET, P. and HEKKERT, P. Appraisal patterns of emotions in human-product interaction. International Journal of Design, 2009, vol. 3, no 2, p. 41-51.

DESMET, P. Designing emotions. Tese (PhD in Industrial Design). Delft University of Technology, Holanda. 2002.

DESMET, P. Special issue editorial : design \& emotion. International Journal of Design, 2009, vol. 3, no 2, p. 1-6.

ELIZAGARATE, V. Marketing de Ciudades. Madrid : Editora Pirámide. 2003.

FREIRE-MEDEIROS, B. A favela que se vê e que se vende : reflexões e polêmicas em torno de um destino turístico. Revista Brasileira de Ciências Sociais, 2007, vol. 22, no 65, p. 61-72.

FRIJDA, N.H. The emotions. Cambridge : Cambridge University Press. 1986.

KOTLER, P., ASPLUND, C., REIN, I. and HAIDER, D. Marketing Places Europe : how to attract investments, industries, residents and visitors to cities, communities, regions and nations in Europe. London : Pearson Education Ltd. 1999.

KOTLER, P., REIDER, D.H. and HEIN, I. Marketing places. New York : Free Press. 1993.

LAZARUS, R.S. Emotion and adaptation. Oxford : Oxford University Press. 1991.

MORGAN, N., PRITCHARD, A. and PIGGOTT, R. The creation of a powerful niche destination brand. Journal of Brand Management, 2002, vol. 9, no 4, p. 335-354.

MORGAN, N., PRITCHARD, A. and PIGGOTT, R. Destination branding and the role of the stakeholders : The case of New Zealand. Journal of Vacation Marketing, 2003, vol. 9, no 3, p. 285-299.

MORGAN, N., PRITCHARD, A. and PRIDE, R. Destination Branding : creating the unique destination proposition. 2ed. New York : Routledge. 2007.

NADAL, P. Nove lugares que odeiam os turistas. El país, 4 Jun 2017. Disponível em : https://brasil.elpais.com/brasil/2017/06/01/elviajero/1496315476_605835.html

OLIVEIRA, J.P., ANJOS, F.A. and LEITE, F.C.L. O potencial da paisagem urbana como atratividade turística : um estudo sobre a paisagem de Brasília-DF. Interações (Campo Grande), 2008, vol. 9, no 2, p. 159-169.

PORTER, M. E. Estratégia Competitiva. São Paulo : Campus. 1986.

QUELUZ, M.L.P. Design \& Identidade. Curitiba : UTFPR. 2008.

REIS, A. Participação do usuário no projeto da habitação popular. Ambiente Construído, 1997, vol. 1, no 1, p. 31-44.

REIS, A. and LAY, M. Avaliação da qualidade de projetos : uma abordagem perceptiva e cognitiva. Ambiente Construído, 2006, vol. 6, no 3, p. 21-34.

RHEINGANTZ, P.A. and ALCANTARA, D. Cognição experiencial, observação incorporada e sustentabilidade na avaliação pós-ocupação de ambientes urbanos. Ambiente Construído, 2007, vol. 7, no 1, p. 35-46.

RIO 2016. Disponível em: www.rio2016.org. Acesso em 26.06.2015.

SANTOS, J.R. Cenários experienciais para a redução da ansiedade : uma investigação com futures mestrandos do processo de busca de informações sobre os cursos. Dissertação (Mestrado em Design). Universidade do Vale dos Sinos. Porto Alegre. 2013.

SAVIGLIANO, M.E. Destino Buenos Aires : tango-turismo sexual cinematográfico. Cadernos Pagu, 2005, vol. 25, p. 327-356.

SCHERER, K.R. What are emotions? And how can they be measured? Social Science Information, 2005, vol. 44, no 4, p. 695-729.

SILVA, M.F.P.S. Antigos processos e novas tendências da urbanização norte-americana contemporânea. Cadernos Metrópole, 2014, vol. 16, no 32, p. 365-390.

SWARBROOKE, J. and HORNER, S. Consumer behaviour in tourism. Oxford : Butterworth-Heinemann. 1999.

TALAVERA, A.S. Turismo cultural, culturas turísticas. Horizontes Antropológicos, 2003, vol. 20, p. 31-57. 
TASCI, A. and KOZAK, M. Destination brands vs destination images : Do we know what we mean? Journal of Vacation Marketing, 2006, vol. 12, no 4, p. 299-317.

TONETTO, L.M.; DESMET, P. Natural language in measuring user emotions : a qualitative approach to quantitative survey-based emotion measurement. In: International Conference on Design \& Emotion, 8, 2012, London. Proceedings... London, Design \& Emotion Society.

TONETTO, L.M., TAROUCO, F. and GREGGIANIN, M. O design para estímulo a experiências territoriais com a arte. Revista Pós, 2015, vol. 21, no 36, p. 1-20.

WALT DISNEY WORLD. Disponível em: https://disneyworld.disney.go.com Acesso em 26.06.2015. 